\title{
Using Videography to Quantify Landscape-Level Availability of Habitat for Grazers: An Example with Emperor Geese in Western Alaska
}

\author{
BRYCE C. LAKE, ${ }^{1,2}$ MARK S. LINDBERG, ${ }^{1}$ JOEL A. SCHMUTZ, ${ }^{3}$ R. MICHAEL ANTHONY ${ }^{3}$ and FRED J. BROERMAN ${ }^{4}$
}

\author{
(Received 28 July 2005; accepted in revised form 21 November 2005)
}

\begin{abstract}
We present a videography approach to estimating large-scale availability of grazing lawns, an important food resource used by broods of emperor geese (Chen canagica) on the Yukon-Kuskokwim Delta, Alaska. Sampling was conducted in 1999, 2003, and 2004 at six locations that encompassed $~ 40 \%$ of the North American population of breeding emperor geese. We conducted ground truthing in 2003 and 2004 to estimate how accurately grazing lawn was classified. Overall, classification accuracy for grazing lawn and non-grazing lawn habitat was greater than $91 \%$. Availability of grazing lawns was stable among years, but varied both among and within locations. Some locations have up to three times as much available grazing lawn, which in combination with densities of geese, likely represents dramatic variation in per capita food availability. Our results suggest that videography is a useful way to sample quickly across a large region and accurately identify fine-scale habitats. We present its use for estimating the availability of a preferred food resource for emperor geese, but the method could be applied to many other cases.
\end{abstract}

Key words: Alaska, Carex, emperor goose, Chen canagica, grazing lawn, Yukon-Kuskokwim Delta, videography

RÉSUMÉ. Nous présentons une méthode vidéographique pour évaluer, à grande échelle, la disponibilité des pâturages, une importante ressource alimentaire pour les couvées d'oies empereurs (Chen canagica) du delta Yukon-Kuskokwim, en Alaska. Des échantillonnages ont été effectués en 1999, 2003 et 2004 à six emplacements visant environ $40 \%$ de la population nord-américaine d'oies empereurs nicheuses. Nous avons réalisé des vérifications au sol en 2003 et en 2004 dans le but d'estimer dans quelle mesure les pâturages étaient bien classés. Dans l'ensemble, l'exactitude du classement des habitats destinés au pâturage et de ceux qui ne sont pas destinés au pâturage dépassait les $91 \%$. La disponibilité des pâturages était stable au fil des ans, mais variait d'un emplacement à l'autre et au sein de ceux-ci. Certains emplacements ont trois fois plus de pâturages disponibles que d'autres. Cela, allié aux densités d'oies, représente vraisemblablement des écarts remarquables pour ce qui est de la disponibilité de nourriture par tête. Nos résultats laissent supposer que la vidéographie représente une bonne manière de faire des échantillonnages rapides dans de grandes régions et de repérer avec prévision les habitats à petite échelle. Nous présentons l'emploi de cette méthode pour évaluer la disponibilité d'une source alimentaire préférée de l'oie empereur, méthode qui pourrait être employée dans bien d'autres cas.

Mots clés : Alaska, Carex, oie empereur, Chen canagica, pâturage, delta Yukon-Kuskokwim, vidéographie

Traduit pour la revue Arctic par Nicole Giguère.

\section{INTRODUCTION}

In Arctic and Subarctic ecosystems, geese are primary consumers during the summer months (Kerbes et al., 1990; Gauthier et al., 2004), when they graze heavily on nitrogen-rich vegetation (Cargill and Jefferies, 1984; Person et al., 1998). Food is often limited in these northern regions (Sedinger and Raveling, 1984; Williams et al., 1993), and the growth and survival of juvenile geese are particularly sensitive to variation in the quality and quantity of food plants (Lindholm et al., 1994; Leafloor et al., 1998; Lepage et al., 1998).

On the Yukon-Kuskokwim Delta (YKD) of Alaska, broods of emperor geese (Chen canagica), black brant
(Branta bernicla nigricans), and cackling geese (B. hutchinsii minima) all forage and rear their broods in Carex subspathacea grazing lawns (Schmutz and Laing, 2002). Such communities of $C$. subspathacea are distributed throughout the Holarctic (Hultén, 1990) and are used by many populations and species of geese (Cargill and Jefferies, 1984; Sedinger et al., 2001). On the YKD, these grazing lawns range in size from $10 \mathrm{~cm}$ wide linear strips to $0.25 \mathrm{~km}^{2}$ patches (Person et al., 1998). Previous efforts to quantify the availability of this food resource have used ground crews (Kincheloe and Stehn, 1991; Jorgenson, 2000) or a combination of ground crews and color infrared photos (Tande and Jennings, 1986; Babcock and Ely, 1994). However, applying these methods at a landscape

\footnotetext{
${ }^{1}$ Institute of Arctic Biology and Department of Biology and Wildlife, University of Alaska Fairbanks, Fairbanks, Alaska 99775, U.S.A.

${ }^{2}$ Corresponding author: Bryce_Lake@ fws.gov; present address: U.S. Fish and Wildlife Service, Yukon Delta National Wildlife Refuge, P.O. Box 346, Bethel, Alaska 99559, U.S.A.

${ }^{3}$ U.S. Geological Survey, Alaska Science Center, 1011 E. Tudor Road, Anchorage, Alaska 99503, U.S.A.

${ }^{4}$ U.S. Fish and Wildlife Service, Yukon Delta National Wildlife Refuge, P.O. Box 346, Bethel, Alaska 99559, U.S.A.
} 
level has proved prohibitively difficult because of the large time investment in sampling, the logistical challenges of working in a remote setting, and the high associated costs.

It is of interest, therefore, to develop a quick, relatively inexpensive method that can identify grazing lawn habitat accurately and be applied on a large scale. Satellite-based remote sensing is increasingly being used to assess variation in land cover (Foody, 2002; Stow et al., 2004) and presents a suite of methods for quantifying food availability across a large area. In situations where higher resolution is needed, videography is an attractive alternative to remote sensing because it can detect finer-scale, patchily distributed features (Markus et al., 2003) and also can be applied on a similar spatial scale.

At a single colony location for black brant on the YKD, it was noted that videography for estimating the abundance of nests (Anthony et al., 1995) could also be used to identify fine-scale plant communities, such as grazing lawns, although the accuracy of identification was not investigated (Person et al., 2003). We applied these same techniques in order to examine the utility of videography for assessing landscape-level variation in availability of grazing lawns.

We present data from videography conducted during 1999-2004 at six locations on the YKD and from ground truthing conducted during 2003-04. In our sampling, we targeted locations used by broods of emperor geese. This species forages almost exclusively in grazing lawns during a critical period for growth and development of goslings, and its population numbers have been depressed, possibly because of poor recruitment (Schmutz, 2001; Schmutz and Laing, 2002; Anderson et al., 2003). No landscape-level assessment of this food resource had been conducted previously. We describe here the methods we used, the accuracy of classifying grazing lawn habitat, and the importance of variation in grazing lawn availability to broods of emperor geese.

\section{STUDY AREA}

We conducted videography sampling across the outer fringe of the YKD. This region is a coastal salt marsh maintained by large flooding events and daily influxes of brackish water from the numerous rivers and sloughs permeating the landscape (Kincheloe and Stehn, 1991). Species diversity of vegetation is low, and continuous meadows of $C$. ramenskii and $C$. rariflora dominate the landscape (Babcock and Ely, 1994; Jorgenson, 2000). Along the interface of $C$. ramenskii meadows and also along coastal margins, riparian mudflats, and pond margins are patchily distributed swards of $C$. subspathacea (Kincheloe and Stehn, 1991; Jorgenson, 2000), which foraging geese prefer because of its high nutrient content (Sedinger and Raveling, 1984; Laing and Raveling, 1993; Ruess et al., 1997). Grazing pressures on C. subspathacea are high (Person et al., 1998), and adult geese sometimes forage in the adjacent, less nutritious $C$. ramenskii community (Ruess et al., 1997). If intensively grazed, $C$. ramenskii is maintained in a form that is morphologically and nutritionally similar to C. subspathacea (Person et al., 2003). In this paper, we use the term "grazing lawn" to refer both to $C$. subspathacea and to $C$. ramenskii that has reverted to a form indistinguishable from C. subspathacea. Other dominant habitats in this region include sloughlevee (consisting of Arctophila fulva, C. lyngbyaei, Deschampsia caespitosa, Elymus arenarius, Poa arctica, and Triglochin palustris) and uplands of Empetrum nigrum, Sphagnum spp., Betula nana, and Cladina rangiferina (Kincheloe and Stehn, 1991; Babcock and Ely, 1994; Jorgenson, 2000).

\section{METHODS}

\section{Videography Flights}

We used aerial videography (Anthony et al., 1995; Person et al., 2003) to sample habitats used by broods of emperor geese (Fig. 1). Flights were conducted in early June of 1999, 2003, and 2004, prior to hatching of emperor goose eggs. Information about the distribution of emperor goose broods (Bowman and Larned, 2000; C. Ely, unpubl. data) was used to delineate the six locations sampled, and 4-13 transects were flown at each location, depending on its size (Fig. 1). For each location, transects were spaced so as to ensure spatial coverage with no possibility of overlap across transects. Total flight time needed to sample all 52 transects was approximately 16 hours. The locations we sampled encompassed about $40 \%$ of the North American population of breeding emperor geese (U.S. Fish and Wildlife Service, unpubl. data).

Two digital cameras (mini-DV format) mounted near the aft bulkhead of a Cessna 206 aircraft recorded vegetation on the ground while flying about $150 \mathrm{~m}$ above ground level at a speed of approximately $160 \mathrm{~km} / \mathrm{h}$. The cameras were connected to the avionics system of the aircraft so that the two-person flight crew could annotate the video. A color monitor received images from the cameras in the aircraft. A GPS receiver linked to a laptop computer recorded the latitude and longitude of the aircraft each second, as well as the transect number, time, and date. When recording of latitude and longitude were not continuous ( $13 \%$ of the time), we interpolated the latitude and longitude from adjacent locations. The location of the moving aircraft relative to each transect was displayed in real time on the computer screen. In 1999 and 2004, one camera was set to record a telephoto view $(72 \mathrm{~mm}$ focal length; $\sim 69 \mathrm{~m}^{2}$ on the ground; Fig. 2) and the other camera recorded a wide view (16 mm focal length; $1387 \mathrm{~m}^{2}$ on the ground; Fig. 2), but in 2003 both cameras were mistakenly set to record a telephoto view. Each year we flew along the same transects, but the vegetation recorded by 


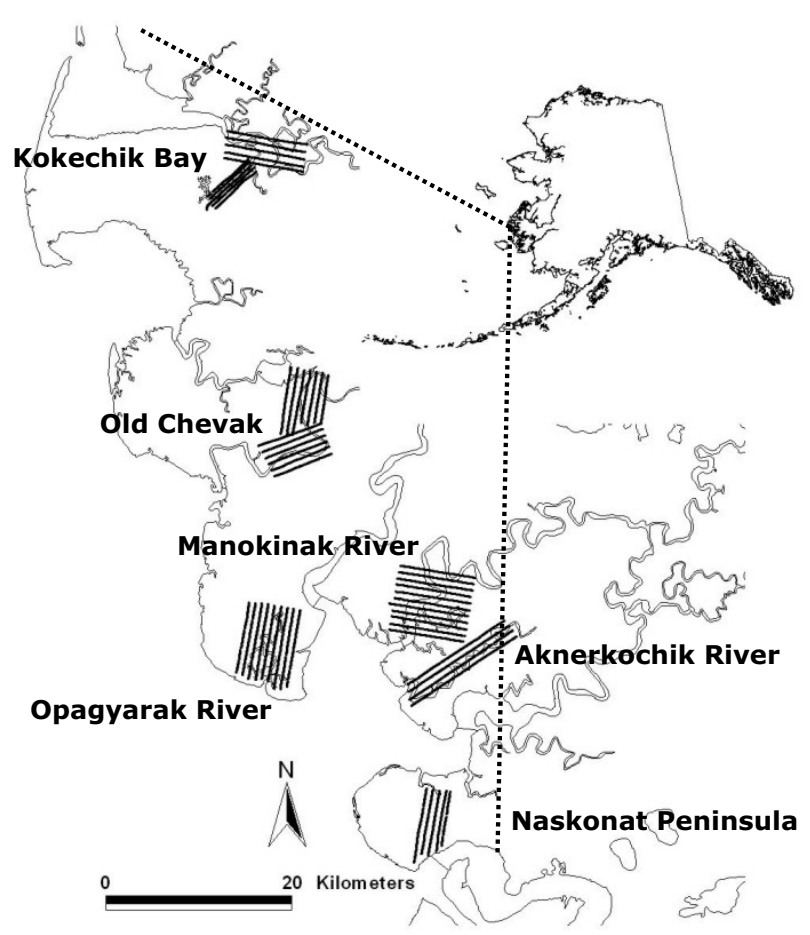

FIG. 1. Distribution of videography transects across the Yukon-Kuskokwim Delta, Alaska. Aknerkochik River, Kokechik Bay, Manokinak River, Old Chevak, and Opagyarak River were sampled in 1999, 2003, and 2004, and Naskonat Peninsula was sampled in 1999 and 2003.

the videography was different because of the small coverage of the telephoto view and deviations from the transect caused by wind gusts, imprecision of GPS locations, and other uncontrollable factors.

\section{Sampling Videography Data}

Prior to sampling, we established eight habitat categories that described all of the sampled area. We chose a priori to limit habitats to eight categories, with the expectation that this would limit classification error yet still provide meaningful resolution. These categories were (1) grazing lawn (C. subspathacea and reverted C. ramenskii), (2) sedge meadow (primarily $C$. ramenskii and $C$. rariflora), (3) slough-levee (primarily Elymus arenarius, Poa arctica, and Deschampsia caespitosa), (4) upland (primarily Empetrum nigrum, Sphagnum spp., and Betula nana), (5) mud, (6) pond or lake, (7) river or slough, and (8) other (primarily pieces of driftwood; Kincheloe and Stehn, 1991; Babcock and Ely, 1994; Jorgenson, 2000). While we collected information on all eight categories, our objective was to present only availability of grazing lawns, as this habitat is most relevant to broods of emperor geese (Laing and Raveling, 1993; Schmutz, 2001; Schmutz and Laing, 2002).

After each field season, we displayed the video using two S-video monitors connected to VCRs, which displayed images from both the telephoto and wide views collected in 1999 and 2004 and the telephoto view collected in 2003. We were able to match images from the

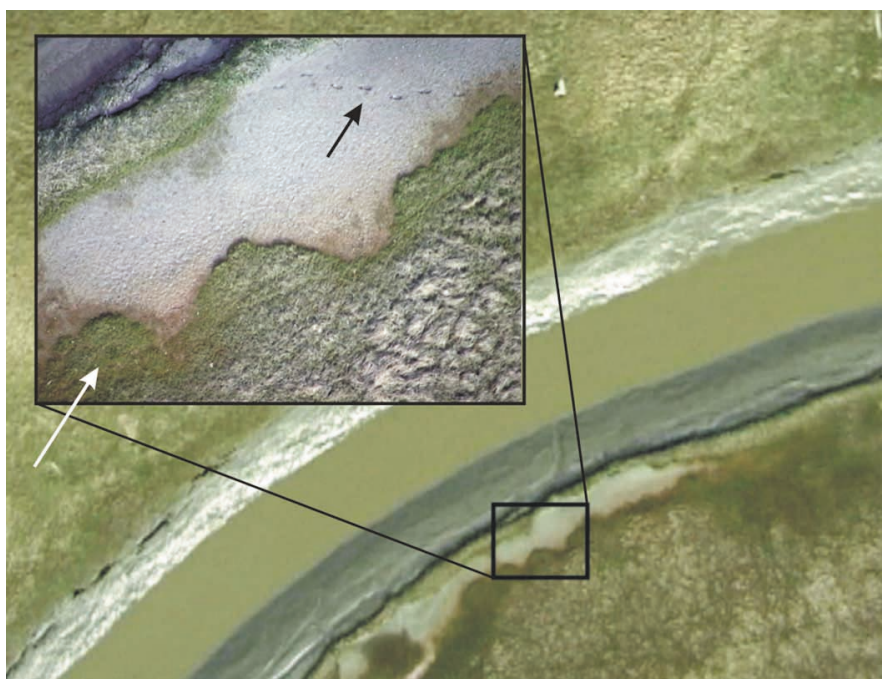

FIG. 2. Corresponding images from the telephoto and wide views captured from the videography. In the telephoto view (inset), the black arrow points to footprints crossing a patch of mud and the white arrow to a patch of grazing lawn in the lower left corner, while smaller patches of grazing lawn can be seen along the interface of mud. Other areas with grazing lawn can be seen in the wide view.

telephoto and wide views using the time stamp from each one-second segment of videotape. This allowed simultaneous viewing of the segment from the telephoto view on one monitor and the location of the telephoto segment within the wide view on the other monitor (Fig. 2). We then sampled the videotape by stratifying by transect within each location. We defined the sample unit as a one-second segment of the videotape (30 frames/second), and we randomly chose 150-160 one-second segments within each location, each separated by a minimum of $200 \mathrm{~m}$. For each selected segment, we overlaid a set of 180 systematically distributed dots onto the telephoto view monitor and visually assigned each dot to one of the eight habitat categories. Each one-second stop of the videotape displayed most (but not all) of the actual segment, and we classified only the habitat on the visible portion. The percent availability of grazing lawns was the proportion of those 180 dots that were classified as grazing lawn. In addition, using the wide view from 1999 and 2004, we assigned collections of dots as being adjacent to a pond or river in order to compare availability of grazing lawns adjacent to these features. One study (Person, 2001) hypothesized that vegetation at inland locations, for example, around pond margins, may exhibit a more plastic response to grazing, which in turn could contribute to differences in grazing lawn availability.

Grazing lawns are distributed about river corridors (Kincheloe and Stehn, 1991), and transects were generally oriented parallel to rivers (Fig. 1). However, rivers on the YKD commonly alter course, and because the plane flying a straight transect could not follow this course, we potentially sampled habitat outside of the distribution of grazing lawns. Consequently, we were concerned that raw estimates of grazing lawn availability might be biased low, 
TABLE 1. Numbers of videotape segments included in analysis of variation in grazing lawn extent among years and locations. For the analysis of grazing lawn extent within locations, we included all segments except those from the year 2003 and those from Naskonat Peninsula. Values in parentheses indicate percentage of videotape sampled.

\begin{tabular}{|c|c|c|c|c|c|c|c|}
\hline Year & Aknerkochik River & Kokechik Bay & Manokinak River & Naskonat Peninsula & Old Chevak & Opagyarak River & Total \\
\hline 1999 & $152(7 \%)$ & $148(4 \%)$ & $147(4 \%)$ & $149(12 \%)$ & $136(5 \%)$ & $139(5.5 \%)$ & 871 \\
\hline 2003 & $151(8 \%)$ & $142(4 \%)$ & $148(5 \%)$ & $147(12 \%)$ & $135(5 \%)$ & $140(5.5 \%)$ & 863 \\
\hline 2004 & $149(7 \%)$ & $143(5 \%)$ & $142(4 \%)$ & 0 & $132(4 \%)$ & $141(4.5 \%)$ & 707 \\
\hline Total & 452 & 433 & 437 & 296 & 403 & 420 & 2441 \\
\hline
\end{tabular}

and that the magnitude of this bias might vary among locations, according to the variable juxtaposition of transects to rivers. To correct for this potential source of bias, we made an ad hoc adjustment to our data. We first calculated the distance from each grazing lawn to the nearest river edge, using the GPS points collected for each second of the videotape, a shapefile that displayed the rivers, and an algorithm in ARCVIEW. For each of the six locations, we then determined the maximum distance from sampled grazing lawns to rivers. We truncated data for each location at that distance, and excluded observations beyond the maximum distance. As a result, sample sizes included in our analyses of grazing lawn differed among locations and years (Table 1).

\section{Ground Truthing}

We conducted ground truthing in 2003 and 2004 to assess how accurately we had classified grazing lawn and non-grazing lawn habitat with the videography. In 2003, prior to the videography flight, we randomly placed five $1 \mathrm{~km}$ long transects on the ground within the Manokinak River location. Along each transect, we placed five large, white X-shaped markers on the ground about $200 \mathrm{~m}$ apart. The aircraft flew over these transects, recording the vegetation below. However, because of the difficulty of maintaining the aircraft in a straight line, we captured only 18 of the 25 markers on the videotape. From the videography, we printed color images that displayed the markers and surrounding habitat. We returned to the field about three weeks later with these images, and after locating each marker, classified habitat shown on the corresponding image.

We used different methodology in 2004 to expand our ground-truthing efforts to another location. After the videography was conducted and we had sampled the videotape, we randomly selected 150 previously sampled videotape segments, 75 from Manokinak River and 75 from Old Chevak, to locate on the ground. We created a color paper printout of each segment that contained both the telephoto and wide views and the corresponding coordinates for the second during which both segments were captured. We used handheld GPS receivers to locate each segment's general area on the ground. We then used the corresponding wide view to match pond, meadow, and river configurations, which allowed us to align ourselves and locate the vegetation on the ground that matched that on the telephoto view. For many segments, it was not possible to pinpoint the telephoto view precisely within the wide view, and because we did not want to induce error associated with co-registration, we omitted these segments, which reduced our sample size to 21 at Manokinak River and 16 at Old Chevak. We do not believe this omission caused bias in our classification, which is described in more detail below.

In both years, we classified habitats observed directly on the ground to compare with our independent classification of these same habitats as observed from the videography segment. For both ground and videographybased classification, multiple categories of habitat often occurred within a single segment. When that happened, observers delineated breaks in habitat type and classified the different types. As in the videography-based classification, points were assigned to the ground-truthing classification. The difference in points between the ground- and videography-based classifications was used to estimate classification accuracy.

\section{Data Analysis - Ground Truthing}

We used user's and producer's accuracy, standard statistics in remote sensing applications (Congalton, 1991; Verbyla, 1995; Foody, 2002), to estimate the accuracy at which we classified grazing lawn and non-grazing lawn habitat from the videography. User's accuracy reflects how often a given habitat (e.g., grazing lawn) that is detected on the ground is accurately classified as grazing lawn on the videotape. Producer's accuracy reflects the proportion of all videography-based classifications of a given habitat (e.g., grazing lawn) that are in fact that habitat, as evaluated from ground-based observations. User's and producer's accuracy are reported as percentages, with a measure of $100 \%$ indicating no error. Use of producer's and user's accuracy requires that three assumptions be met (Verbyla, 1995): (1) the ground-truthing data are representative of the entire classification, (2) the groundtruthing data and classified segment are perfectly coregistered, and (3) there are no errors in the groundtruthing data. We believe we met these assumptions. Although we were unable to conduct ground truthing at four videography locations, the Manokinak River and Old Chevak locations were representative of the range of habitat types in the total study area. Old Chevak is the most inland and elevated location, whereas Manokinak River is 
more coastal and similar in habitat features and topography to the other locations sampled (Kincheloe and Stehn, 1991). We were unable to locate many of the randomly selected ground-truthing segments in 2004 and some in 2003. Most segments were omitted because they lacked sufficient pond, meadow, or river signatures to enable their detection, or they comprised a single, large, homogenous habitat, not of grazing lawn, which made it difficult to pinpoint the telephoto view precisely within the wide view. This type of omission could bias classification accuracy if the ground-truthing sample were skewed towards easily detectable habitats. However, the relative proportions of different habitat types observed on the groundbased classification were nearly equal to those observed on the larger, videography-based classification, indicating that the ground data were representative. The data were perfectly co-registered because we were able to locate, on the ground, the segments we sampled on the videography. We minimized the potential for error in the ground-truthing data by training observers in identification of habitat types. If some observers were unsure of habitat type, they collected detailed notes on vegetation characteristics and habitat type was later classified by the first or third author.

\section{Data Analyses - Variation in Grazing Lawn Availability}

We conducted two analyses of variation in grazing lawn availability. For the analysis of variation among years and locations, we included data from Aknerkochik River, Kokechik Bay, Manokinak River, Old Chevak, and Opagyarak River in 1999, 2003, and 2004, and Naskonat Peninsula in 1999 and 2003 (Table 1). We were able to collect information on the adjacency of grazing lawns to ponds and rivers only in 1999 and 2004. Thus, we restricted the analysis of variation within locations to 1999 and 2004, and we excluded Naskonat Peninsula, which was not surveyed in 2004.

We constructed models to examine hypotheses about variation in grazing lawn availability. We expected that grazing lawn availability might differ among locations because of variation in topography or edaphic conditions (Ruess et al., 1997) or among years because of interactions with herbivores (Person et al., 2003). Therefore, the models we considered contained different combinations of the variables location, year, and trend in year (Table 2). To address variation within locations, we examined whether addition of the pond/river variable to the best-fitting model from the prior analysis resulted in improved model fit.

We used an information-theoretic approach (Burnham and Anderson, 1998) to evaluate the relative support for the models we proposed to address our hypotheses. We used Proc GLM (SAS Institute Inc., 2001) to generate estimates of grazing lawn availability and evaluate the relative support for our candidate models. Because our response variable was a proportion, we applied arcsine transformations to grazing lawn availability before analysis in order to better meet the distributional assumptions of
TABLE 2. Candidate models for investigation of variation in grazing lawn availability among years and locations. Estimates are based on sampling conducted at Aknerkochik River, Kokechik Bay, Manokinak River, Old Chevak, and Opagyarak River in 1999, 2003, and 2004, and at Naskonat Peninsula in 1999 and 2003. Models are ranked by relative differences in AIC values.

\begin{tabular}{lcccc}
\hline \hline Model $^{1}$ & $K^{2}$ & $\log (L)^{3}$ & $\Delta \mathrm{AIC}$ & $w^{4}$ \\
\hline Location & 7 & 4192.93 & 0.00 & 0.68 \\
Location + YEAR & 8 & 4193.01 & 1.80 & 0.28 \\
Location + Year & 10 & 4193.11 & 5.58 & 0.04 \\
Location * Year & 18 & 4194.55 & 18.27 & 0.00 \\
Null & 2 & 4176.68 & 27.41 & 0.00 \\
Year & 4 & 4176.92 & 30.87 & 0.00 \\
\hline \hline
\end{tabular}

${ }^{1}$ The "+" between variables indicates an additive effect; the "**" denotes an interaction.

${ }^{2}$ Number of parameters.

${ }^{3}$ Maximized log-likelihood.

${ }^{4}$ Weight of evidence for being the best-approximating model for each group.

${ }^{5}$ Linear time trend.

linear models (Sokal and Rohlf, 1995). Relative differences in Akaike's Information Criterion $(\triangle \mathrm{AIC})$, or Akaike's Information Criterion corrected for finite sample size $(\triangle \mathrm{AIC} c)$ were used to discriminate among competing models (Burnham and Anderson, 1998). We computed back-transformed, least-squares estimates of grazing lawn availability from the best-approximating model in each analysis.

\section{RESULTS}

We estimated producer's and user's accuracy from 55 videotape segments later located on the ground: 18 at Manokinak River in 2003, 21 at Manokinak River in 2004, and 16 at Old Chevak in 2004. We analyzed variation among years and locations using 2441 segments sampled in 1999, 2003, and 2004 at five locations and in 1999 and 2003 at one location. To assess variation within locations, we analyzed 1429 segments sampled at five locations in 1999 and 2004. The percentage of videotape sampled varied among locations and ranged from $4 \%$ to $12 \%$ within a year (Table 1).

\section{Detection of Grazing Lawn}

Producer's accuracy for grazing lawn ranged from $97.5 \%$ to $100 \%$ and user's accuracy ranged from $91.6 \%$ to $98.7 \%$ (Table 3). Non-grazing lawn ranged from $99.7 \%$ to $99.9 \%$ for producer's accuracy and from $99.8 \%$ to $100 \%$ for user's accuracy. There was a small annual difference (range $0.2-7.1 \%$ ) in producer's and user's accuracy for grazing lawn and non-grazing lawn at Manokinak River in 2003 and 2004 (Table 3). Similarly, there was a small spatial difference (range $0.1-2.5 \%$ ) in producer's and 
TABLE 3. Producer's and user's accuracy for classification of grazing lawn and non-grazing lawn habitat. Producer's accuracy reflects the error in values omitted from a category that should have been included. User's accuracy reflects error from values incorrectly classified. User's and producer's accuracy are reported as percentages, with a measure of $100 \%$ indicating no error.

\begin{tabular}{|c|c|c|c|c|c|}
\hline \multirow[b]{2}{*}{ Location - Year } & \multicolumn{2}{|c|}{ Producer's Accuracy } & \multicolumn{2}{|c|}{ User's Accuracy } & \multirow[b]{2}{*}{ Overall } \\
\hline & Grazing Lawn & Non-Grazing Lawn & Grazing Lawn & Non-Grazing Lawn & \\
\hline Manokinak River - 2003 & 100 & 99.7 & 91.6 & 100 & 99.8 \\
\hline Manokinak River - 2004 & 97.5 & 99.9 & 98.7 & 99.8 & 99.8 \\
\hline Old Chevak - 2004 & 100 & 99.8 & 96.8 & 100 & 99.8 \\
\hline Annual Difference ${ }^{1}$ & 2.5 & 0.2 & 7.1 & 0.2 & - \\
\hline Spatial Difference $^{2}$ & 2.5 & 0.1 & 1.9 & 0.2 & - \\
\hline
\end{tabular}

${ }^{1}$ Difference between Manokinak River in 2003 and in 2004.

${ }^{2}$ Difference between Manokinak River in 2004 and Old Chevak in 2004.

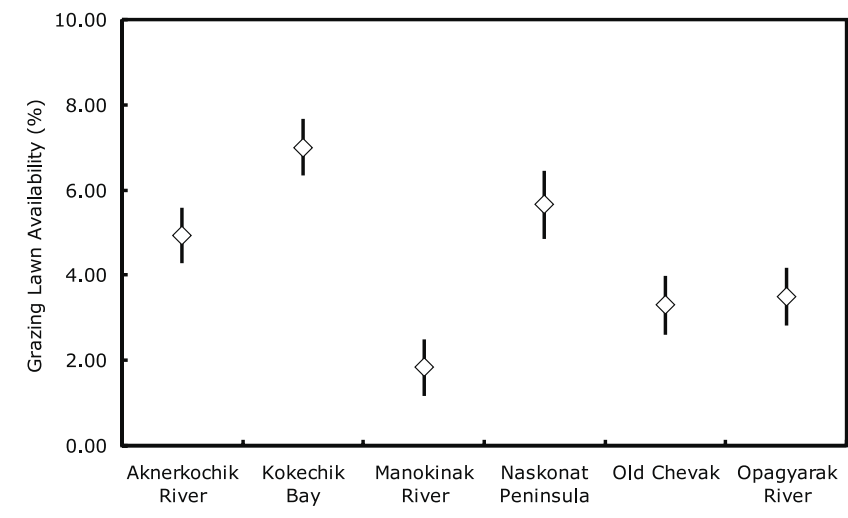

FIG. 3. Availability of grazing lawns (Mean \pm SE) at six locations used by broods of emperor geese. The best-approximating model included an effect of location, but did not include year (1999, 2003, and 2004).

user's accuracy for grazing lawn and non-grazing lawn in 2004 at Manokinak River and Old Chevak.

\section{Variation Among Years and Locations}

The best-approximating model indicated that grazing lawn availability varied among locations, but not among years (Table 3). There was some support for a model incorporating a trend in year $(\triangle \mathrm{AIC}=1.80)$, but the trend coefficient was not distinguishable from zero $(\beta Y E A R=$ $-0.0006, \mathrm{SE}=0.001)$. Mean estimates $( \pm \mathrm{SE})$ of availability varied from $1.8 \%$ to $7 \%( \pm 0.7)$ among locations; they were highest at Kokechik Bay and lowest at Manokinak River (Fig. 3). Aknerkochik River and Naskonat Peninsula had similar availability of grazing lawns that was greater than that of Old Chevak and Opagyarak River, which were also similar (Fig. 3).

\section{Variation Within Locations}

Grazing lawn availability varied with adjacency to a pond or river, as a model that incorporated an additive effect of location and pond/river resulted in better fit than a model with location only $(\triangle \mathrm{AIC} c=16.45)$, or a model with an interaction of location and pond/river $(\Delta \mathrm{AIC} c=$

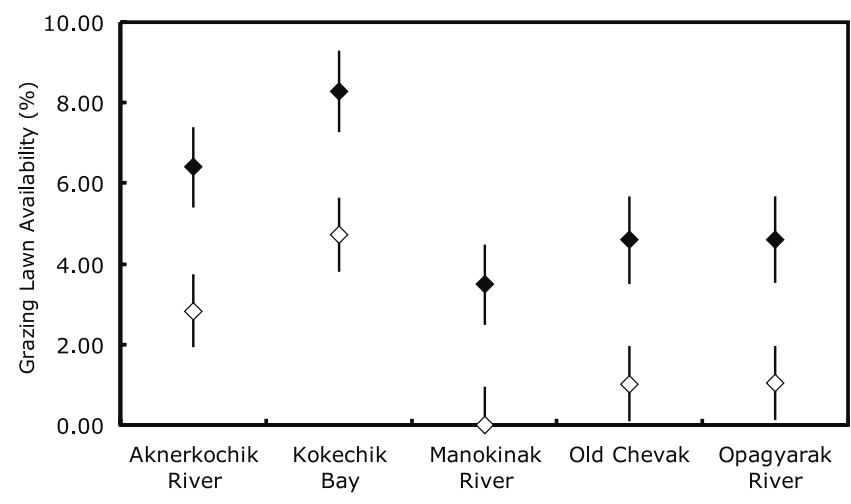

FIG. 4. Availability of grazing lawns (Mean \pm SE) adjacent to ponds (closed diamonds) and rivers (open diamonds). The best-approximating model included an additive effect of location and pond/river, but did not include year (1999 and 2004).

7.49). Grazing lawn availability was greater adjacent to ponds than to rivers (difference $=0.04, \mathrm{SE}=0.01$ ). Among locations, mean estimates ( $\pm \mathrm{SE}$ ) of grazing lawn availability adjacent to ponds varied from $3.5 \%$ to $8.3 \%( \pm 0.9)$, and adjacent to rivers varied from $0.0 \%$ to $4.7 \%$ ( \pm 1.0$)$ (Fig. 4).

\section{DISCUSSION}

\section{Utility of Aerial Videography}

Aerial videography is useful for quickly sampling a large region and accurately identifying fine-scale, patchily distributed habitats. A study with objectives similar to ours (Jano et al., 1998) used satellite imagery to sample habitats used by lesser snow geese (Anser caerulescens caerulescens) on a large scale, but it was only able to distinguish vegetation from non-vegetation and could not identify grazing lawns used by broods of that species. Our videography method combined quick, relatively inexpensive sampling with the ability to identify fine-scale habitat patches, such as grazing lawns, across large spatial extents. Possible alternatives to videography include QuickBird and IKONOS imagery. However, even the 
current resolution of these methods $(0.6-1 \mathrm{~m})$ may be insufficient to detect small (10 cm wide), linear strips of grazing lawn. Furthermore, cloud cover that may obscure satellite methods but is not sufficient to prevent aircraft operation and videography is common on the YKD. We suggest that videography has broad application and is an attractive alternative to ground-based sampling or satellite remote sensing. In addition, a combination of videography and satellite remote sensing (Markus et al., 2003) may be a practical way to increase spatial coverage.

Using aerial videography, we were able to classify grazing lawn and non-grazing lawn habitat with a high degree of accuracy. Thomlinson et al. (1999) suggested a minimum criteria for land cover classification of $70 \%$ accuracy per category and $85 \%$ accuracy overall. Our efforts produced results that exceeded those criteria for both grazing lawn and non-grazing lawn.

Temporal differences in accuracy may have been due to variation among years in weather or lighting conditions, or phenology of green-up. Nevertheless, accurate identification of habitat types was still possible. Under similar videography conditions, Anthony et al. (1995) reported that even under poor weather and lighting conditions, precise estimation of brant populations was possible with videography. Spatial differences in identification of grazing lawn and non-grazing lawn habitat were minimal. Overall, high accuracy of detecting grazing lawns was likely related to their comparatively short growth form.

\section{Variation in Grazing Lawn Availability}

Grazing lawn availability in our study varied from $1.8 \%$ to $7 \%$ among locations. Because broods of emperor geese spend more than $80 \%$ of their time in this habitat feeding (Schmutz and Laing, 2002), a difference of 1.5-2x in the amount of their primary food base likely represents a biologically relevant difference in food availability. Nevertheless, it is also important to consider densities of geese, especially in light of recent research that suggests body mass of pre-fledging emperor geese, which is sensitive to food availability, declines with increasing interspecific goose densities (Schmutz and Laing, 2002). Surveys of nesting geese in spring (U.S. Fish and Wildlife Service, unpubl. data) indicate that densities are relatively similar across the locations we sampled. Consequently, we suggest that variation among locations in grazing lawn likely equates to dramatic differences in the per capita food availability.

Within locations, we observed that grazing lawn availability adjacent to ponds was up to $3.5 \times$ as great as that adjacent to rivers. Schmutz (2001) reported that broods of emperor geese most strongly selected saline pond rather than mudflats bordering rivers. Unlike Schmutz's (2001) conjecture of what habitats were used for foraging, our results suggest that emperor geese may have selected these pond habitats for their greater food availability. In response to mammalian predators, broods of emperor geese commonly move onto mudflats or rivers (Laing and Raveling, 1993). Given the difference in grazing lawn availability adjacent to ponds versus rivers, broods may also face trade-offs between minimizing risk of predation and maximizing the amount of available forage.

The changing availability of grazing lawns on the YKD is due in part to interactions with grazers (Ruess et al., 1997; Person et al., 2003). Person et al. (2003) observed an increase in grazing lawn availability during 1991-99 in response to increased densities and grazing pressures by herbivores, predominantly black brant. We did not detect a temporal change in the availability of grazing lawns during 1999-2004, a time of relative stability or decline in density of the composite goose community on the YKD (Anthony, 2004; Eldridge and Hodges, 2004). Nonetheless, the potential for feedbacks between goose densities and grazing lawn availability (Person et al., 2003) suggests that future monitoring of both the grazers and the food resource is warranted. Our videography technique provides that opportunity for the food resource, which until now has not been examined at such a large scale.

\section{ACKNOWLEDGEMENTS}

M. Rearden, Yukon Delta National Wildlife Refuge, and the Alaska Science Center provided financial and logistical support for this project. Yukon Delta National Wildlife Refuge, the Department of Biology and Wildlife and Graduate School, University of Alaska Fairbanks provided direct financial support. Additional funding was provided by the California Waterfowl Association - Dennis Raveling Scholarship. P. Liedberg and P. Anderson skillfully piloted the airplane and are thanked for many safe hours of flying. We acknowledge the efforts of P. Fontaine, P. Lemons, D. Rizzolo, and $\mathrm{M}$. Shepherd, who refused to quit searching for the groundtruthing points. B. Person graciously shared his experience at identifying grazing lawn habitat with videography. C. Mulder, E. Murphy, R. Rockwell, J. Sedinger, and an anonymous reviewer provided comments on earlier drafts of the manuscript.

\section{REFERENCES}

ANDERSON, P.D., LARNED, W.W., MALLEK, E.J., DAU, C.P., and STEHN, R.A. 2003. Monitoring emperor goose populations by aerial counts and the proportion of young - fall 2002. U.S. Fish and Wildlife Service Report, Anchorage, Alaska. Unpubl. ms. Available at the Office of Migratory Bird Management, 1011 East Tudor Road, Anchorage, Alaska 99503.

ANTHONY, R.M. 2004. Aerial surveys of brant colonies on Yukon Delta NWR in 2004. U.S. Department of the Interior, Geological Survey, Anchorage, AK. Unpubl. ms. Available at the U.S.G.S. Biological Science Office, 1011 East Tudor Road, Anchorage, Alaska 99503.

ANTHONY, R.M., ANDERSON, W.H., SEDINGER, J.S., and McDONALD, L.L. 1995. Estimating populations of nesting brant using aerial videography. Wildlife Society Bulletin 23:80-87. 
BABCOCK, C.A., and ELY, C.R. 1994. Classification of vegetation communities in which geese rear broods on the YukonKuskokwim Delta, Alaska. Canadian Journal of Botany 72: 1294-1301.

BOWMAN, T.D., and LARNED, W.W. 2000. Emperor goose production on Yukon Delta NWR in 1999. U.S. Fish and Wildlife Service Report, Anchorage, Alaska. Unpubl. ms. Available at the Office of Migratory Bird Management, 1011 East Tudor Road, Anchorage, Alaska 99503.

BURNHAM, K.P., and ANDERSON, D.R. 1998. Model selection and inference: A practical information-theoretic approach. New York: Springer-Verlag.

CARGILL, S.M., and JEFFERIES, R.L. 1984. The effects of grazing by lesser snow geese on the vegetation of a sub-Arctic salt marsh. Journal of Applied Ecology 21:669-686.

CONGALTON, R.G. 1991. A review of assessing the accuracy of classifications of remotely sensed data. Remote Sensing of Environment 37(1):35-46.

ELDRIDGE, W.D., and HODGES, J. 2004. Report to the Pacific Flyway Committee on the 1985-2004 coastal zone YukonKuskokwim Delta goose survey of geese, swans, and sandhill cranes. U.S. Department of the Interior, Fish and Wildlife Service, Anchorage, Alaska. Unpubl.ms. Available at the Office of Migratory Bird Management, 1011 East Tudor Road, Anchorage, Alaska 99503.

FOODY, G.M. 2002. Status of land cover classification accuracy assessment. Remote Sensing of Environment 80:185-201.

GAUTHIER, G., BETY, J., GIROUX, J.-F., and ROCHEFORT, L. 2004. Trophic interactions in a High Arctic snow goose colony. Integrative and Comparative Biology 44:119-129.

HULTÉN, E. 1990. Flora of Alaska and neighboring territories. Stanford, California: Stanford University Press.

JANO, A.P., JEFFERIES, R.L., and ROCKWELL, R.F. 1998. The detection of vegetational change by multitemporal analysis of LANDSAT data: The effects of goose foraging. Journal of Ecology 86:93-99.

JORGENSON, M.T. 2000. Hierarchical organization of ecosystems at multiple spatial scales on the Yukon-Kuskokwim Delta, Alaska, U.S.A. Arctic, Antarctic, and Alpine Research 32: $221-239$.

KERBES, R.H., KOTANEN, P.M., and JEFFERIES, R.L. 1990. Destruction of wetlands by lesser snow geese: A keystone species on the west coast of Hudson Bay. Journal of Applied Ecology 27:242-258.

KINCHELOE, K.L., and STEHN, R.A. 1991. Vegetation patterns and environmental gradients in coastal meadows on the YukonKuskokwim Delta, Alaska. Canadian Journal of Botany 69: 1616-1627.

LAING, K.K., and RAVELING, D.G. 1993. Habitat and food selection by emperor goose goslings. Condor 95:879-888.

LEAFLOOR, J.O., ANKNEY, C.D., and RUSCH, D.H. 1998. Environmental effects on body size of Canada geese. Auk 115: 26-33.

LEPAGE, D.G., GAUTHIER, G., and REED, A. 1998. Seasonal variation in growth of greater snow goose goslings: The role of food supply. Oecologia 114:226-235.
LINDHOLM, A., GAUTHIER, G., and DESROCHERS, A. 1994. Effects of hatch date and food supply on gosling growth in Arctic-nesting greater snow geese. Condor 96:898-908.

MARKUS, T., CAVALIERI, D.J., TSCHUDI, M.A., and IVANOFF, A. 2003. Comparison of aerial video and Landsat 7 data over ponded sea ice. Remote Sensing of Environment 86(4):458-469.

PERSON, B.T. 2001. Herbivore-mediated effects on ecosystem processes in a near-Arctic salt marsh. PhD thesis, University of Alaska Fairbanks.

PERSON, B.T., BABCOCK, C.A., and RUESS, R.W. 1998. Forage variation in brood-rearing areas used by Pacific black brant geese on the Yukon-Kuskokwim delta, Alaska. Journal of Ecology 86:243-259.

PERSON, B.T., HERZOG, M.P., RUESS, R.W., SEDINGER, J.S., ANTHONY, R.M., and BABCOCK, C.A. 2003. Feedback dynamics of grazing lawns: Coupling vegetation change with animal growth. Oecologia 135:583-592.

RUESS, R.W., ULIASSI, D.D., MULDER, C.P.H., and PERSON, B.T. 1997. Growth responses of Carex ramenskii to defoliation, salinity, and nitrogen availability: Implications for geeseecosystem dynamics in western Alaska. Ecoscience 4: $170-178$.

SAS INSTITUTE INC. 2001. The SAS system for Windows. Version 8.2. Cary, North Carolina: SAS Institute Inc.

SCHMUTZ, J.A. 2001. Selection of habitats by emperor geese during brood rearing. Waterbirds 24:394-401.

SCHMUTZ, J.A., and LAING, K.K. 2002. Variation in foraging behavior and body mass in broods of emperor geese (Chen canagica): Evidence for interspecific density dependence. Auk 119:996-1009.

SEDINGER, J.S., and RAVELING, D.G. 1984. Dietary selectivity in relation to availability and quality of food for goslings of cackling geese. Auk 101:295-306.

SEDINGER, J.S., HERZOG, M.P., PERSON, B.T., KIRK, M.T., OBRITCHKEWITCH, T., MARTIN, P.P., and STICKNEY, A.A. 2001. Large-scale variation in growth of black brant goslings related to food availability. Auk 118:1088-1095.

SOKAL, R.R., and ROHLF, F.J. 1995. Biometry. New York: W.H. Freeman and Company.

STOW, D.A., HOPE, A., McGUIRE, D., VERBYLA, D., GAMON, J., HUEMMRICH, F., HOUSTON, S., RACINE, C., STURM, M., TAPE, K., HINZMAN, L., YOSHIKAWA, K., TWEEDIE, G., NOYLE, B., SILAPASWAN, C., DOUGLAS, D., GRIFFITH, B., JIA, G., EPSTEIN, H., WALKER, D., DAESCHNER, S., PETERSEN, A., ZHOU, L., and MYNENI, R. 2004. Remote sensing of vegetation and land-cover change in Arctic tundra ecosystems. Remote Sensing of Environment 89(3):281-308.

TANDE, G.F., and JENNINGS, T.W. 1986. Classification and mapping of tundra near Hazen Bay, Yukon Delta National Wildlife Refuge, Alaska. U.S. Department of the Interior, Fish and Wildlife Service, Anchorage, Alaska. Unpubl. ms. Available at the U.S. Fish and Wildlife Service, 1011 East Tudor Road, Anchorage, Alaska 99503.

THOMLINSON, J.R., BOLSTAD, P.V., and COHEN, W.B. 1999. Coordinating methodologies for scaling landcover classifications 
260 • B.C. LAKE et al.

from site-specific to global: Steps toward validating global map products. Remote Sensing of Environment 70(1):16-28.

VERBYLA, D.L. 1995. Satellite remote sensing of natural resources. New York: Lewis Publishers.
WILLIAMS, T.D., COOCH, E.G., JEFFERIES, R.L., and COOKE, F. 1993. Environmental degradation, food limitation, and reproductive output: Juvenile survival in lesser snow geese. Journal of Animal Ecology 62:766-777. 